\title{
CRACK PROPAGATION FOR CONCRETE FLAT PLATES USING XFEM METHOD
}

\author{
RWAYDA KH. S. AL HAMD ${ }^{*}$, MARTIN GILLIE ${ }^{\dagger}$, YONG WANG ${ }^{\dagger \dagger}$ AND ASAD S. \\ ALBOSTAMI \\ University of Manchester \\ Manchester, UK \\ e-mail: rwayda.alhamd@manchester.ac.uk \\ ${ }^{\dagger}$ University of Manchester \\ Manchester, UK \\ e-mail: martin.gillie@manchester.ac.uk \\ ${ }^{\dagger \dagger}$ University of Manchester \\ Manchester, UK \\ e-mail: yong.wang@manchester.ac.uk \\ ${ }^{\dagger \dagger}$ University of Manchester \\ Manchester, UK \\ e-mail: asad.albostami@manchester.ac.uk
}

Key words: crack propagation, XFEM, concrete flat plate, punching shear.

\begin{abstract}
Flat plate concrete structures are easy to construct and cheap to build. However, they are susceptible to a type of brittle failure known as "punching shear", where columns punch through the floor leading to progressive collapse. This is a particularly dangerous type of failure as it occurs suddenly and without warning. A finite element model was developed and validated based on the author's previous tests for a square slab with a single column stub. This arrangement simulates the type of column to slab arrangement found in many office buildings. The failure mechanics were examined and the model gave a good agreement with the experimental results identifying the correct crack pattern and the failure loads.

A 2-d axisymmetric model was then developed representing a circular column to model the punching crack propagation in detail. This was done using the extended finite element method (XFEM). The XFEM results showed the good agreement between crack location and areas of highest principal strain and were able to capture crack propagation and the effect this has on the stress state under punching failure. It is concluded that explicit modelling of fracture is beneficial in order to capture the full response of the slab and that continuum models are insufficient to do this.
\end{abstract}

\section{INTRODUCTION}

Flat plate concrete structures, where a floor plate is connected directly to columns without the aid of beams (Figure 1), are widely used in buildings such as offices because of advantages including reduced storey heights, rapid construction and the ability to place columns at arbitrary locations [1]. A key failure mechanism that must be guarded against in flat plate design is "punching shear", where an area of floor plate fails in shear in the vicinity of a column (Figure 1). This form of failure is brittle, and hence highly dangerous, but not fully understood. There have been several failures in recent times due to punching shear, some resulting in fatalities [2].

The collapse of several buildings due to punching shear means it is important to fully understand the mechanics involved. Since failuret is known to result from cracks, the mechanics cannot be fully understood using the normal finite element method, which does 


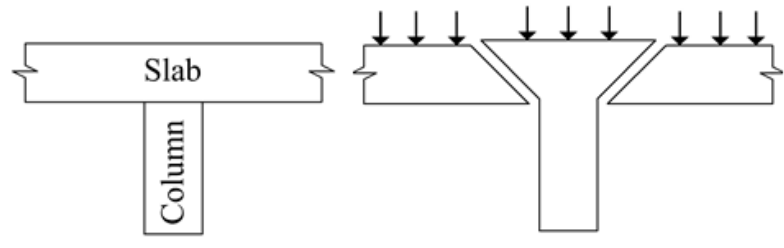

Figure 1 Schematic diagram of a flat plate structure and the punching shear failure mechanism.

not model discrete cracks well. To address this problem, this paper presents an analysis of punching shear behaviour using extended finite element method (XFEM), which is able to capture crack initiation and propagation.

Previous attempts at numerically modelling punching shear behaviour are limited, probably due to the inherent difficulties in effectively representing the behaviour of reinforced concrete numerically. Finite element modelling of punching shear behaviour has been studied by several researchers $[3,4]$ who were able to identify the stress and strain states induced by punching behaviour but, due to the inability to model cracks, could not identify the failure mechanisms.

XFEM captures the main cracking modes including opening, sliding and anti-plane cracks [5]. Punching shear cracks can be considered a combination of opening cracks and sliding cracks since the crack will began from bending cracks (opening cracks) before propagating into shear cracks (sliding cracks), forming the famous cone shape of punching shear [6] (Figure 1). Therefore, XFEM may be expected to offer a suitable means of modelling punching shear .

Using XFEM to model concrete cracking in structures has had limited application previously and concentrated mainly on the shear behaviour of beams [7-9]. In this paper, the use of the XFEM is adopted to simulate the more complicated phenomena that occur in slabs for the first time.

\section{MODELING APPROACH}

\subsection{Model validation}

To validate the general modelling approach a non-XFEM model was developed to simulate the punching shear behaviour seen prior to failure in recent tests [10] (Figure 2) using the finite element package Abaqus. The model used 8-noded hexahedral solid elements with reduced integration for all concrete parts of test specimens (Figure 3), together with truss (axial forces only) elements to represent the steel reinforcement. Full bond between the two materials was assumed [10].

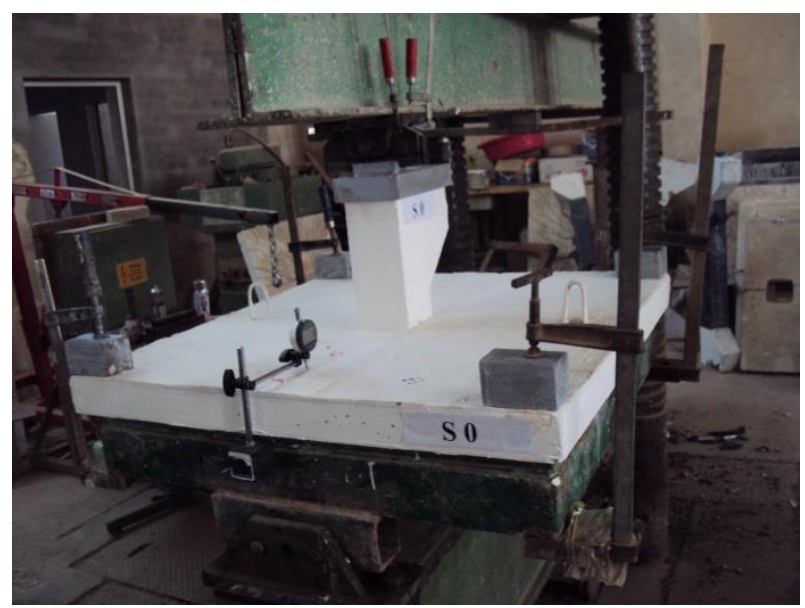

Figure 2 Punching shear test.

Concrete was represented using the damaged plasticity model provided with Abaqus [1113] with the uniaxial compressive stress-strain relationship taken from Eurocode 2 [14]. Uniaxial tension behaviour was taken from Wang and Hus [15]. The main parameters used for the damage plasticity model were taken from Lubliner et al. [11] [12] [16] [17]. Steel behaviour was taken from measured behaviour in coupon tests and modelled using a von Mises yield criterion. The concrete damage plasticity parameters were chosen according to relevant literature; where the dilatation angle for concrete should be between $15^{\circ}$ to $40^{\circ}$, the shape factor of the yield surface $(K)$ is between 1 to $2 / 3$, the eccentricity of the dilation of concrete related to wide range confining pressure and in this case was taking as 0.1 and $f_{b} / f_{c o}$ stress ratio should be between 1.12 to $1.16[3,11,13,18]$. 


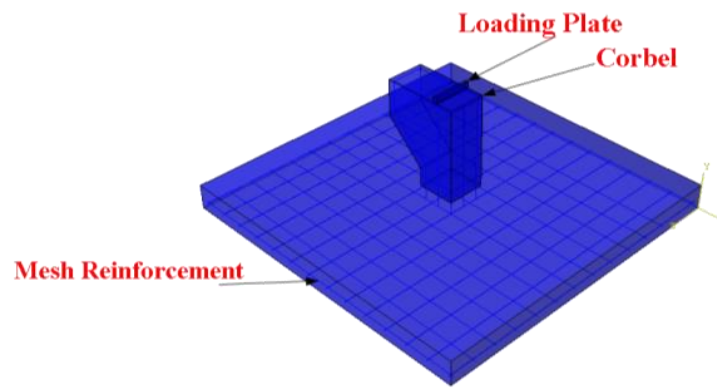

Figure 3 Model layout.

Abaqus offers two numerical methods to analyse unstable nonlinear models: a general static analysis and a Riks static analysis [13]. Both types of analysis were used to validate the numerical model against experimental results as shown in Figure 4. Both produced good comparisons but due to the numerical scheme, the general static results were not able to capture structural softening behaviour.

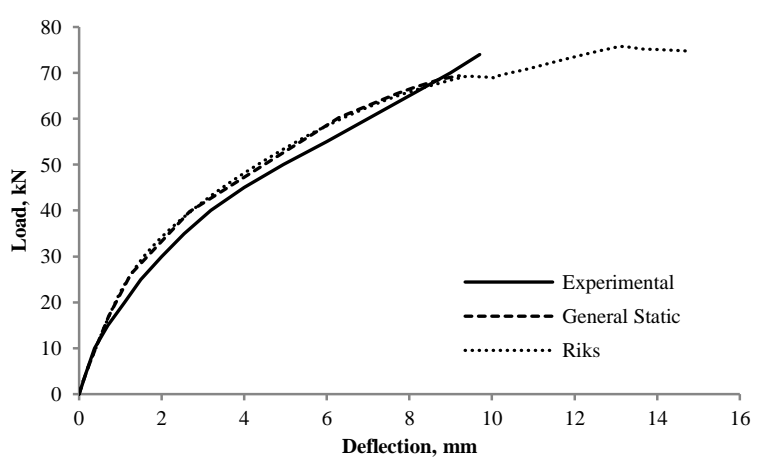

Figure 4 Load - central deflection curve for validation models.

Figure 5 shows the maximum principal strains predicted by the model, which indicate high strains near the column-slab connection, as expected for punching shear development.

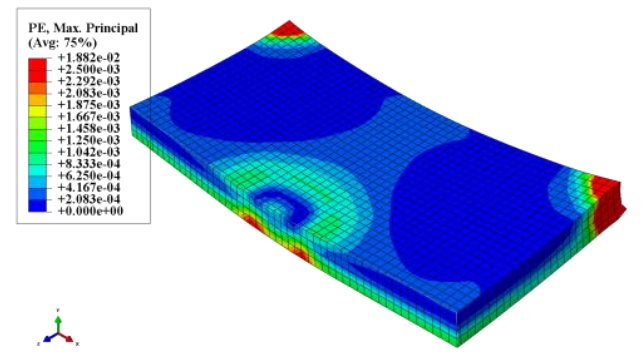

Figure 5 Compression face and a cut through the thickness for the validation model.

After this validation, a similar but axisymmetric model was developed to understand the stress state in the connection;
XFEM behaviour was included in this model as detailed below.

\subsection{XFEM assumptions}

Modelling cracking using XFEM in Abaqus uses the method developed by Belytschko and Black [19] who proposed local enrichment functions to incorporate the presence of a discontinuity caused by the cracking of a material. In Abaqus, crack propagation depends on the nodal displacements of the elements near the crack tip. The approximation for the vector function for the displacement is [13]:

$u=\sum_{I=1}^{N} N_{1}(x)\left[u_{1}+H(x) a_{1}+\sum_{a=1}^{4} F_{a}(x) b_{1}^{a}\right]$

Where;

$u$ : displacement vector

$N$ : shape function

$H$ : jump function

$a_{1}$ : nodal enriched degree of freedom vector

$f_{a}$ : asymptotic crack-tip functions

$b_{1}^{a}$ : nodal enriched degree of freedom vector

A cohesive segments approach is used in this simulation which is a numerical method to represent the crack as several sets of cohesive segments overlapping[20] shown in Figure 6.

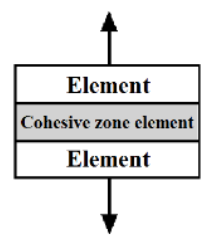

Figure 6 Cohesive segments approach.

The prediction of the initiation of a crack is based on the maximum principle stress; crack initiation occurs if:

$$
f=\frac{\left|\sigma_{\max }\right|}{\sigma_{\max }}
$$

Where;

$\sigma_{\max }^{\circ}$ : Maximum allowable principle stress

$\sigma_{\max }:$ Maximum normal principle stress

$$
\left|\sigma_{\max }\right|= \begin{cases}2, & \sigma_{\max }<2 \\ \sigma_{\max }, & \sigma_{\max } \geq 2\end{cases}
$$


Equation 3 implies that the purely compressive stress state does not initiate damage[13].

\subsection{XFEM model}

The 2-d axisymmetric model developed to capture crack propagation model is shown in Figure 7. The model is half scale; the slab dimensions are (560 $\mathrm{mm} \times 100 \mathrm{~mm}$ thick) and the column dimensions are $(60 \mathrm{~mm} \times 320$ $\mathrm{mm})$.

The same concrete material was used in this model with the steel rebar represented as a truss element embedded in the concrete.

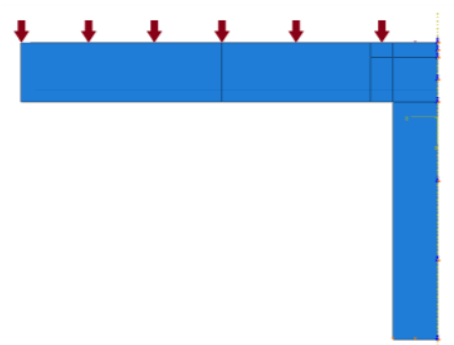

Figure 7 Axisymetric model.

The stress distribution is complicated in the slab column connection and this stress state produces several cracks.

It has been observed experimentally that punching shear cracks start from a bending crack then develop into a shear crack, causing the famous cone shape of punching shear [6]. To capture this numerically, the area shaded red in Figure 8 had XFEM cracking control applied. The blue areas were not able to develop XFEM cracks to ensure numerical stability.

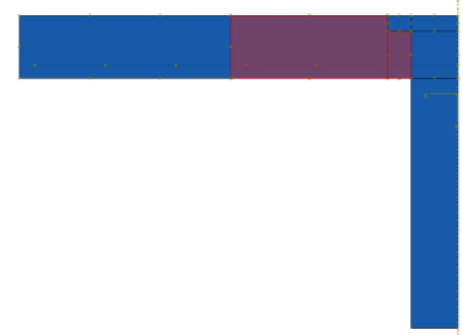

Figure 8 XFEM zone.

A mesh size of $10 \mathrm{~mm}$ was adopted in this model because the concrete used had an aggregate maximum size of $10 \mathrm{~mm}$ and the mesh size should not exceed the aggregate maximum size according to fib MC [21] (Figure 9).

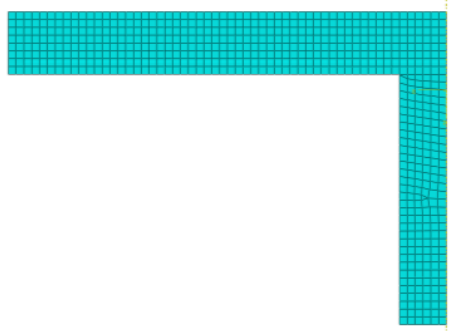

Figure 9 Mesh size.

\section{RESULTS}

\subsection{Crack propagation}

To check that XFEM model is working as expected, load-deflection predictions for the model together with those with the same comparable non-XFEM model are plotted in Figure 10, where good agreement is seen.

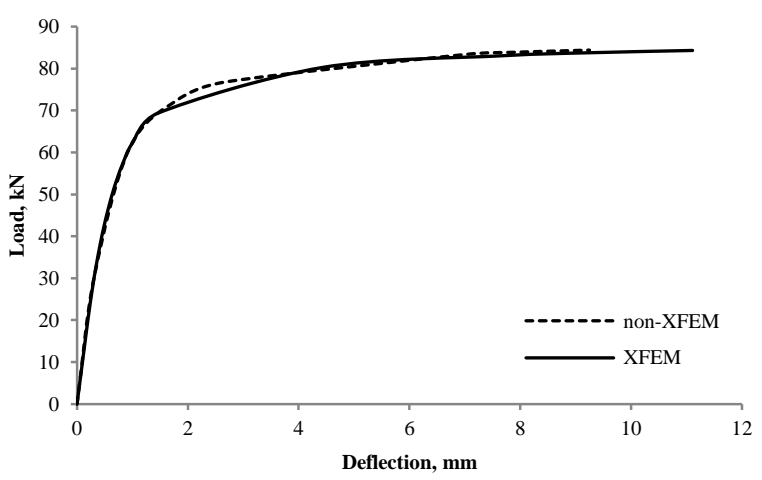

Figure 10 Load deflection curve.

Since the maximum principal stress is main controlling parameter for the approach taken in this simulation and the governing factor in initiating shear failure physically, it is plotted as contour plots for various stages of the analysis in Figure 11 to Figure 14. It can be seen from these plots that the crack is predicted to start as a bending crack and then develop into shear crack, in line with the critical shear crack theory proposed by Muttoni [6]. 


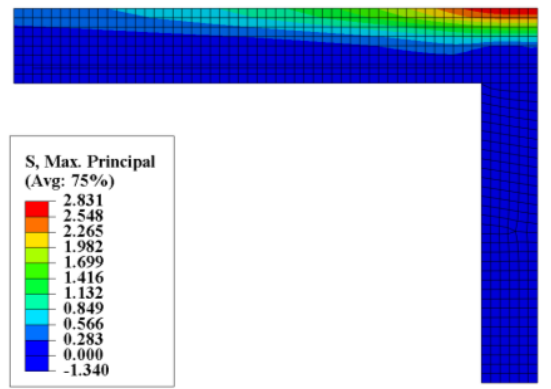

Figure 11 Maximum principal stress at $5 \%$ of maximum load.

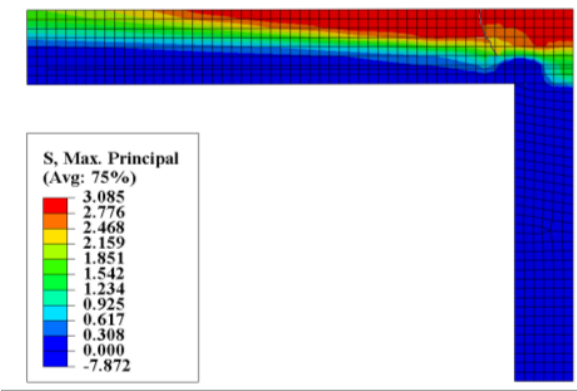

Figure 12 Maximum principal stress at $80 \%$ of maximum load.

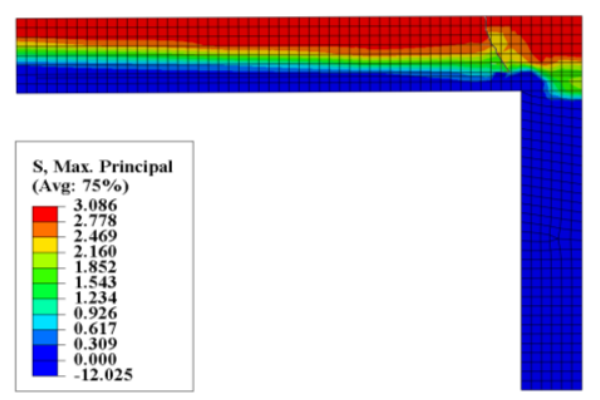

Figure 13 Maximum principal stress at $90 \%$ of maximum load.

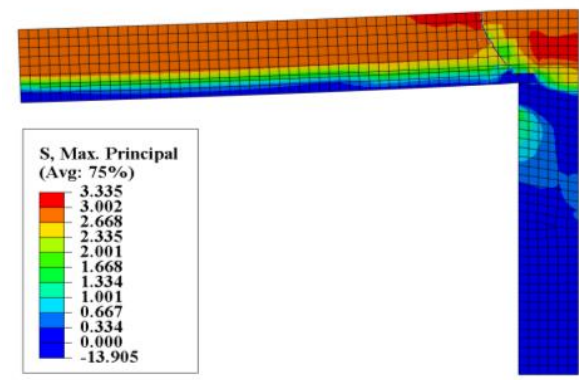

Figure 14 Maximum principal stress at $100 \%$ of maximum load.

The principal stress crack initiation criterion occurs when the plastic strain exceeds zero. By plotting plastic strain (Figure 15) the location of the cracked area can be seen in a similar manner to Figure 5.

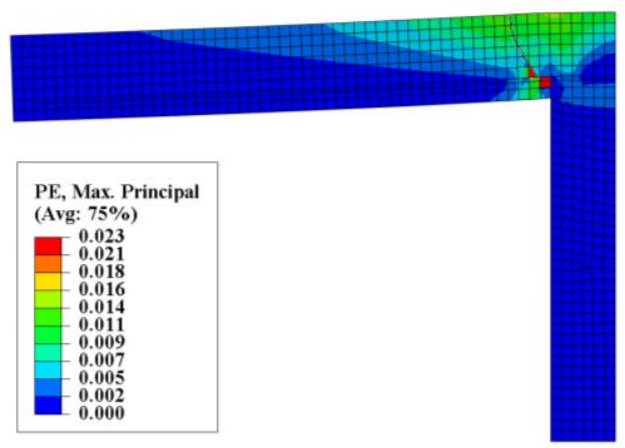

Figure 15 Maximum principal plastic strain.

\subsection{Stress Analysis}

The maximum principle stress and the shear stress are plotted along the cracking path as shown in Figure 16. This path was taken as $45^{\circ}$, which represents the principal shear stress line.

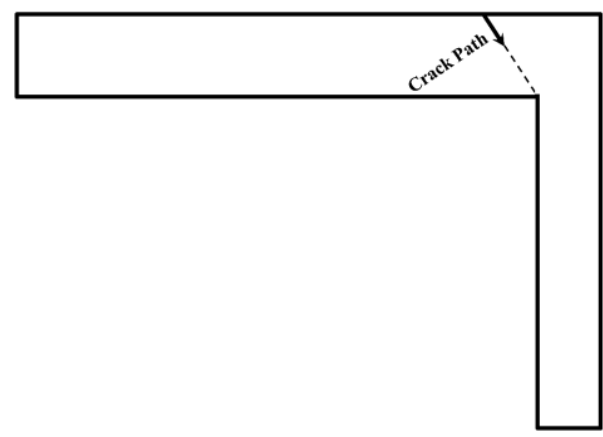

Figure 16 Cracking Path.

It can be seen from Figure 17 and Figure 18 that the crack development has a significant effect. This is important because punching shear design relies on the development of certain stress states in the cracking region, so accurate numerical predictions are needed in numerical models are to be used to aid design.

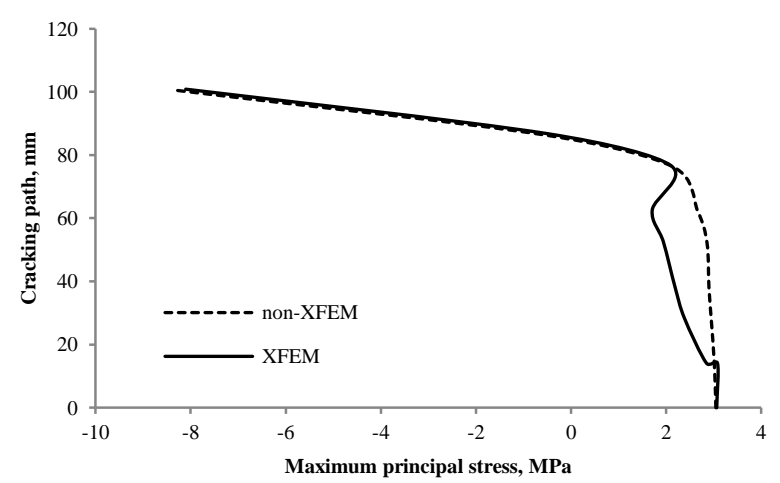

Figure 17 Maximum principal stress along cracking path. 


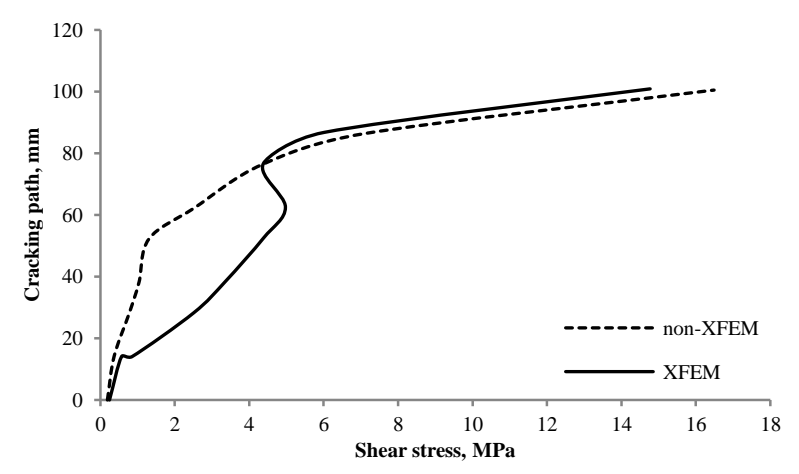

Figure 18 Shear stress along cracking path.

\section{CONCLUSIONS AND RECOMMENDATION}

1- A fracture mechanics approach based on the XFEM method can capture crack propagation leading the punching shear.

2- The modelling approach gives good agreement with the test results and a nonXFEM approach prior to crack development.

3- Significate differences are seen in predicted stress states after cracking occurs. This may be important if results are used for design calculations.

4- There are some limitations for using XFEM approach for predicting punching shear in the model presented. Notably no account is taken of steel-concrete interaction and aggregate interlock, both of which may be important for shear behaviour. Future work will address these limitations.

\section{ACKNOWLEDGEMENTS}

The authors acknowledge the support of The Higher Committee for Education and Development in Iraq (HCED) for the financial support that made this work possible.

\section{REFERENCES}

[1] Ferguson P, Breen J, Jirsa J. Reinforced Concrete Fundamental. 3rd ed. Hoboken: John Wiley \& Sons; 1988.

[2] King S, Delatte NJ. Collapse of 2000 Commonwealth Avenue: Punching Shear Case Study. Journal of Preformance of Constructed Facilites 2004;18:54-61.

[3] Genikomsou AS, Polak MA. Finite Element Analysis of Punching Shear of Concrete Slabs
Using Damaged Plasticity Model in ABAQUS. Engineering Structures 2015;98:38-48.

[4] Wosatko A, Pamin J, Polak MA. Application of Damage-Plasticity Models in Finite Element Analysis of Punching Shear. Computers \& Structures 2015;151:73-85.

[5] Zhuang Z, Liu Z, Cheng B, Liao J. Extended Finite Element Method. First edit. Published by Elsevier Inc.; 2014. doi:http://dx.doi.org/10.1016/B978-0-12407717-1.00001-7.

[6] Muttoni A. Punching Shear Strength of Reinforced Concrete Slabs. ACI Structral Journal 2008;105:440-50.

[7] Roth S, Léger P, Soulaïmani A. A combined XFEM-damage mechanics approach for concrete crack propagation. Computer Methods in Applied Mechanics and Engineering 2015;283:923-55. doi:10.1016/j.cma.2014.10.043.

[8] Unger JF, Eckardt S, Könke C. Modelling of cohesive crack growth in concrete structures with the extended finite element method. Computer Methods in Applied Mechanics and Engineering 2007;196:4087-100. doi:10.1016/j.cma.2007.03.023.

[9] Yang ZJ, Chen J. Finite element modelling of multiple cohesive discrete crack propagation in reinforced concrete beams. Engineering Fracture Mechanics 2005;72:2280-97. doi:10.1016/j.engfracmech.2005.02.004.

[10] Al Hamd RKS, Gillie M, Wang Y, Rasheed MM. Punching Shear - Eccentric Load and Fire Conditions. CONFAB 2015 Conference Proceedings, Glasgow, United Kingdom: ASRANet Ltd; 2015, p. 201-9.

[11] Lubliner J, Oliver J, Oller S, Onate E. A Plastic-Damage Model for Concrete. International Journal of Solids and Structures 1989;25:299-326.

[12] Lee J, Fenves GL. Plastic-Damage Model for Cyclic Loading of Concrete Structures. Journal of Engineering Mechanics 1998;124:892-900.

[13] ABAQUS, User's Manual, Version 6.13. Dassault Systémes Simulia Corp, Providence, Rhode 2013. 
[14] Eurocode 2. Design of Concrete Structures, Part 1-1: General Rules and Rules for Buildings. vol. 3. 2004.

[15] Wang T, Hsu T. Nonlinear Finite Element Analysis of Concrete Structures Using New Constitutive Models. Computers \& Structures 2001;79:2781-91.

[16] Grassl P, Jirásek M. Damage-Plastic Model for Concrete Failure. International Journal of Solids and Structures 2006;43:7166-96.

[17] Jankowiak T, Lodygowski T. Identification of parameters of concrete damage plasticity constitutive model. Foundations of Civil and Environmental ... 2005:53-69.

[18] Chaudhari S V. Modeling of Concrete for Nonlinear Analysis Using Finite Element Code ABAQUS 2012;44:14-8.

[19] Hattori G, Rojas-Díaz R, Sáez A, Sukumar N, García-Sánchez F. New anisotropic crack-tip enrichment functions for the extended finite element method. Computational Mechanics 2012;50:591-601. doi:10.1007/s00466-0120691-0.

[20] Remmers JJC, De Borst R, Needleman A. A cohesive segments method for the simulation of crack growth. Computational Mechanics 2003;31:69-77. doi:10.1007/s00466-0020394-z.

[21] CEB-FIP International Federation for Structural Concrete (fib). fib Model Code 2010. Lausanne, Switzerland: 2013 fédération internationale $\mathrm{du}$ béton / International Federation for Structural Concrete (fib) Postal; 2010. 